\title{
Application of SCOPE-C to measure social inclusion among mental health services users in Hong Kong
}

Chan, K.; Chiu, M.Y.; Evans, S.; Huxley, P.J.; Ng, Y.L.

\section{Community Mental Health Journal}

DOI:

10.1007/s10597-015-9907-z

Published: 01/11/2016

Peer reviewed version

Cyswllt i'r cyhoeddiad / Link to publication

Dyfyniad o'r fersiwn a gyhoeddwyd / Citation for published version (APA):

Chan, K., Chiu, M. Y., Evans, S., Huxley, P. J., \& Ng, Y. L. (2016). Application of SCOPE-C to measure social inclusion among mental health services users in Hong Kong. Community Mental Health Journal, 52(8), 1113-1117. https://doi.org/10.1007/s10597-015-9907-z

\footnotetext{
Hawliau Cyffredinol / General rights

Copyright and moral rights for the publications made accessible in the public portal are retained by the authors and/or other copyright owners and it is a condition of accessing publications that users recognise and abide by the legal requirements associated with these rights.

- Users may download and print one copy of any publication from the public portal for the purpose of private study or research.

- You may not further distribute the material or use it for any profit-making activity or commercial gain

- You may freely distribute the URL identifying the publication in the public portal ?
}

Take down policy

If you believe that this document breaches copyright please contact us providing details, and we will remove access to the work immediately and investigate your claim. 


\title{
Application of SCOPE-C to measure social inclusion among mental health services users in Hong Kong
}

\begin{abstract}
This study describes the construction of the Chinese version of the Social and Communities Opportunities Profile (SCOPE), henceforth, the SCOPE-C, to measure social inclusion among mental health services users in Hong Kong. The SCOPE-C was developed based on conceptmapping and benchmarking of census questions. The questionnaire consisted of 56 items, went through a standardized linguistic validation process and was pilot tested with qualitative feedback from five users of mental health services. Altogether 168 Chinese service users were recruited through various NGO mental health services to have three times face-to-face interview between October 2013 and July 2014. Results indicated that items related to satisfaction with opportunities and perceived opportunities in various social domains had high consistency. Nearly all the Kappa statistics and Pearson correlation coefficients between the baseline and two rounds of re-test were significant. The SCOPE-C was considered a valid instrument for Hong Kong mental health user population.
\end{abstract}

Keywords: inclusive practices; perceived opportunities; social policy; need assessment 


\section{Application of SCOPE-C to measure social inclusion among mental health services users in Hong Kong}

\section{Introduction}

The study of the relationship between social inclusion and mental health has generated

much interest among social services providers as well as social scientists (Huxley et al., 2008). A relevant way of measuring social inclusion benefits both social policy makers and mental health services providers in designing and implementing policies and intervention programmes for mental health services users. The measure can be used as an outcome measure as well as an initial social assessment for agencies (Huxley et al., 2008). A social inclusion index - Social and Communities Opportunities Profile (SCOPE) - was developed and validated in English in UK (Huxley et al., 2006; 2012). The present study aims to demonstrate the process of the development of a Chinese language measure of social inclusion (SCOPE-C) and its application in Hong Kong. Results of the assessment of the SCOPE-C in terms of internal reliability and test-retest reliability over two weeks and over six months will be discussed.

\section{Literature review}

According to The World Bank (2013), social inclusion is a process of ending extreme poverty and cultivating shared prosperity for both individuals and groups in society. It ensures that individuals have a right in deciding factors that influence their lives and that they can access to political, social and physical areas equally.

A review of literature examining links between social inclusion/exclusion and mental health issues identified a rights-based approach and a participation-based approach (Curran et al., 2007; Huxley et al., 2006). A rights-based approach argues that social exclusion is a result of 
denial or non-realization of citizenship rights, including civil, political and social rights. A participation-based approach argues that social inclusion is an opportunity to participate in key functions of the society.

By contrast, we suggest that a social inclusion index should focus on the availability of opportunity to access material and other resources, as well as the subjective perception and satisfaction with this availability. It should also address the extent to which a person participates in various life activities, his or her perceived values of the activities, and his or her intention to participate in these life domains (Evans and Huxley, 2005).

There is a lack of a valid instrument that measures social inclusion directly in different cultures. Developing a reliable and valid inclusion measure will help to improve the accountability of services, as well as providing objective measures of the efficacy of different service intervention programmes. A robust measure of social inclusion (SCOPE) was developed from a concept mapping study in UK (Huxley et al., 2006) and survey data generated from a community sample randomly selected from five areas in England and Wales; a mental health service user sample (MHSUs) from two services set in a south Wales resource centre; and a student sample in a university (Huxley et al., 2012). The SCOPE incorporates objective and subjective indicators of inclusion including the satisfaction with opportunities and perceived opportunities of the above life domains. The SCOPE allows social services providers to evaluate people with mental health problems and can be adopted across a range of community service settings.

The long version SCOPE showed good internal consistency of all scales $(\alpha \geq 0.7)$ and good construct validity. It also demonstrated good discriminant validity between different mental health groups. The English version of the SCOPE demonstrated good internal consistency, test- 
retest reliability over time, and validity (Huxley et al., 2012). All SCOPE domains had characteristics that made them appropriate for factor analytic procedures (Huxley et al., 2012).

The number of items in long version SCOPE was reduced from 121 to 48 to form the short version SCOPE using factor analysis. The short version of SCOPE demonstrates good psychometric properties as well as good discriminant validity between mentally healthy and mentally unhealthy groups (Huxley et al., 2012). The short version SCOPE is more suitable for operational use.

The current study reported the development of the Chinese version of the short version of SCOPE (i.e. SCOPE-C). A concept mapping exercise using focus group interviewing method was conducted to explore the cultural relevancy of social inclusion in Hong Kong. The findings indicated that there were considerable similarities in the understanding of the concept of social inclusion in Hong Kong and the UK (Chan et al., 2013), but with one or two salient differences. For instance, Hong Kong interviewees seldom mentioned an individual's rights to access resources and facilities in society. They put more emphasis on civic responsibility than civil rights. This concept mapping exercise has greatly aided the team to decide what is relevant in the SCOPE scale to the people of Hong Kong. It makes the further translation work by linguist more grounded on actual life experience, rather than just a textual translation of the measurement tool.

Here we report the application of this adapted instrument in Hong Kong at three time points in various social domains. We also examine its internal reliability as well as the test-retest reliability. Various demographic influences on SCOPE-C were examined. Only the short version of SCOPE was used during the development of SCOPE-C.

\section{Methods}


Participants were recruited through five service agencies that work with people with mental health issues in Hong Kong. Altogether 168 individuals who were service users of mental health service centers or halfway houses participated in the study. The sample included only subjects with functional psychoses. They had to have a formal psychiatric diagnosis, have received more than 6 weeks of mental health treatment, and their problems had to be stable over the past six weeks.

Ethical approval was granted by the University's Committee on the Use of Human and Animal Subjects in Teaching and Research. Interested participants were referred to us by six social services providers. Participants were asked to answer questions of a Social and Communities Opportunities Profile (SCOPE-C). They were told that their participation in this study was voluntary and no identifier would be used. The face-to-face individual interviews were conducted in Cantonese dialect (a common dialect used in Hong Kong) and conducted by two interviewers. All interviews were conducted at the premises of the service providers. The second individual interviews were conducted two weeks later. A third round of interviews was conducted six months after the first interview. Participants were offered a payment of HK\$150 (equivalent to US\$20) for those who participated in all three rounds of interviews. Interviews were conducted between October 2013 and July 2014. The interviewing time lasted between 20 to 40 minutes.

The SCOPE-C contains 56 questions covering eight domains of inclusion and general social inclusion. The domains relate to leisure and participation, housing and accommodation, safety, work, financial situation, education, self-reported health, as well as family and social relationships. Subjective items (satisfaction with opportunities and perceived opportunities) and objective items were included in each domain. Satisfactions with opportunities for each domain 
were rated on a 7-point scale that 1 indicated extremely restricted opportunities and 7 indicated plentiful opportunities. Perceived opportunities for each domain were rated on a 5-point scale that 1 equated to feeling terrible and 5 equated to feeling delighted. Objective items such as "Do you currently uses leisure, sports or entertainment facilities", "If you needed someone to lend you a small amount of money, do you know anybody who would be able to do so within one week?" were included in the relevant domains. Questions for the demographic section were modified based on the questions asked in the Hong Kong 2011 Population Census (Hong Kong Census and Statistics Department, 2012). Selected questions in the SCOPE were modified to fit the contexts of Hong Kong. Eight questions were added to the UK SCOPE, including one question in the housing domain about whether the accommodation the respondent lived was

owned or rented by the household, two questions on experience of discrimination in everyday life and the perceived reasons for being discriminated, one long question on health conditions measured by SF-12, and four additional questions in the profile section about place of birth, years lived in Hong Kong, languages spoke at home, and language competency. Readers are welcomed to contact the authors for a copy of the SCOPE-C.

We believe that the SCOPE-C can be used for the Chinese population in the Greater China region and Asia region with some minor changes. First, the question about participation in the national election needed to be revisited. Second, the question on car ownership needed to be replaced by a more relevant indicator of wealth, for example by the size of the accommodation the respondent lived in.

\section{Results}

The sample sizes at round 2 and round 3 were 156 and 142 respectively. This low dropout rate gives us added confidence in our results. All participants were Chinese. Altogether 80 
participants were female and 88 were male. Participants' age on their last birthday ranged from 20 to 65 at baseline $(M=43.95 ; S D=11.21)$. Years they have been living in Hong Kong ranged from 1 to $64(M=39.23 ; S D=14.30)$. Most of them were living in halfway houses or public rental housing units. More than half of them were employed, $20 \%$ were unemployed because of long-term health issues, and a further $16.1 \%$ were unemployed for other reasons. Participants' sources of income were normally social welfare $(66.1 \%)$ or earned income (23.2\%).

For the leisure and participation domain, most participants (74.4\%) use leisure, sports or entertainment facilities currently. A majority $(71.1 \%)$ had a desire to change their leisure opportunities. Most of them did not vote in the 2012 legislative council election (72.1\%). A majority of participants reported that they helped someone voluntarily (64.3\%). For the housing and accommodation domain, years they have lived in their area were $12.17(S D=13.17)$. For the financial domain, participants' average monthly income was HK $\$ 4023.89$ ( $S D=2614.90 ; 1$ $\mathrm{USD}=7.8 \mathrm{HKD})$. About half of them (56.9\%) said someone would lend them a small amount of money if they needed. This person is most likely to be their immediate family (24.1\%) or friends $(21.8 \%)$. For the safety domain, participants perceived that the area they were living were fairly safe. For the health domain, a majority did not visit a general practitioner (GP) or family doctor for physical health (42.3\%) or for mental health (89.9\%). Many of them did not attend a hospital or clinic for a physical health problem $(41.3 \%)$ in the last year, but three-quarter of them visited as a day patient or in-patient for a physical health problem three or more times in the last year. For the family and social relationships domain, most participants (67.9\%) contacted parents once a week or more. The average number of friends reported was $12.05(S D=40.43)$. About half of them (53.6\%) never had friends or neighbours visit their homes.

The internal consistency of the satisfaction with opportunities items and perceived 
opportunities items were 0.82 and 0.67 respectively at baseline. Satisfaction with opportunities was above average of 4 (mid-point of a 7-point scale) for all domains. Highest satisfaction scores were reported for the satisfaction with opportunities for contact with family as well as the satisfaction with opportunities for leisure activities. Perceived opportunities were all close to average of 3 (mid-point of a 5-point scale), with the exception of perceived opportunities for involvement with community groups and organization $(M=3.59)$; at the other extreme, the lowest perceived opportunities score was that for opportunities to increase income $(M=2.68)$.

The Kappa statistics for categorical variables and the Pearson correlation coefficient for ordinal and continuous variables between the baseline and re-test (two weeks) were used. All $K \mathrm{~s}$ or $r \mathrm{~s}$ were significant $(0.23 \leq K \mathrm{~s}$ or $r \mathrm{~s} \leq 0.98)$, with the exception of one item (frequency of visits to GP for mental health). Finally, 142 participants completed the third interview. All Ks or $r \mathrm{~s}$ were significant $(0.14 \leq K$ s or $r \mathrm{~s} \leq 0.98)$.

Demographic analyses on SCOPE-C were also conducted. Results indicated that there were no gender differences on SCOPE-C, except one, that male participants $(M=3.80)$ had higher POpps for involvement with community groups and organisations than female participants $(M=3.38), t(138)=-2.21, p<.05$.

For the type of accommodation, we grouped housing types other than halfway house and public rental housing units as 'others'. There were significant differences in SatOpps to increase income, $F(2,163)=4.25, p<.05$, POpps for suitable housing, $F(2,164)=6.09, p<.01$, POpps for suitable work, $F(2,164)=8.61, p<.001$, POpps to increase income, $F(2,164)=3.21, p$ $<.05$, and average POpps, $F(2,161)=9.58, p<.001$. Post hoc Tukey contrasts showed that participants who were living in halfway house had the highest scores and participants who were living in public house had the lowest scores on SatOpps to increase income ( $M=4.57$ vs $M=$ 
3.95), POpps for suitable housing $(M=3.38$ vs $M=2.66)$, POpps for suitable work $(M=3.19$ vs $M=2.37)$, and average POpps $(M=3.28$ vs $M=2.72)$.

For the employment status, we created a productive group (in paid employment, retired from paid work, looking after family, and self-employed) and a non-productive group (long term sick or disabled and unemployed). Independent $t$-test showed that participants in productive group $(M=4.81)$ scored higher on overall social inclusion than participants in non-productive group $(M=4.36), t(166)=2.05, p<.05$. Employment status was related to better scores on perceived opportunity for suitable housing and overall social inclusion.

For the educational differences, there were significant differences in SatOpps for mental health care, $F(2,162)=3.88, p<.05$, and SatOpps for contact with friends and neighbours, $F(2,162)=4.05, p<.05$. Post hoc Tukey contrasts indicated that participants whose highest qualification were higher (secondary form 7, Diploma/certificate, sub-degree course, and degree course) had the lowest SatOpps for mental health care $(M=4.27)$ and SatOpps for contact with friends and neighbours $(M=4.32)$. In contrast, participants whose highest qualification were lower (no schooling/pre-primary, primary, and secondary form 3) had the highest SatOpps for mental health care $(M=4.88)$ and SatOpps for contact with friends and neighbours $(M=$ 5.02).

For the place of birth, independent $t$-test indicated that there were no significant differences on SCOPE-C, except one item. Participants born in Hong Kong $(M=5.06)$ scored higher on SatOpps to live safely in area than participants who were born in China or Macao $(M=$ 4.68), $t(164)=2.21, p<.05$. Finally, participants' age was negatively correlated with SatOpps for contact with family $(r=-.20, p<.05)$, POpps for suitable work $(r=-.19, p<.05)$, POpps to increase income $(r=-.19, p<.05)$, POpps for education $(r=-.20, p=.01)$, and average POpps $(r$ 
$=-.23, p<.01)($ all older $=$ less $)$.

\section{Discussion}

This study was conducted to examine the application of the Chinese version of the SCOPE to measure social inclusion among mental health services users in Hong Kong at three time points. The inter-item reliability of the eleven satisfaction with opportunities items (SatOpps) $(\alpha=0.82)$ and the five perceived opportunities items (Perceived Opps) $(\alpha=0.67)$ achieved moderate to high internal reliability, with the use of data from three time points. The coefficients were higher than the respective 0.77 and 0.62 of the UK sample (Huxley et al., 2012). The inter-item correlations for the perceived opportunities scale items ranged from 0.18 to 0.40 , with the mean inter-item correlation of 0.28 , similar to that obtained from the UK population sample of 0.25 (Huxley et al., 2012).

Given the short time-span between baseline and 2-week follow-up, the intention was to demonstrate stability over a short period of time, determined by a positive relationship between items at both time points. The $r$-values ranged from 0.23 to 0.98 and Kappa values ranged from 0.10 to 0.89 , showing significant relationships between the scores at the two time points. It is reasonable to see extremely high correlation coefficients between two time points on items that may not change much within a 2-week interval, such as, the number of friends, contact with parents, and opportunity to work among the unemployed participants. This also shows that the participants, in spite of mental health issues, give reliable account of their situation. For other items, there was a good stability of the SCOPE-C over a 2-week interval.

The r-values and K-values in the present study between time 1 and time 2 were lower than the r-values (ranged from 0.62 to 1.0) and Kappa values (ranged from 0.66 to 0.97) reported in the UK study (Huxley et al., 2012). The differences in the figures can be attributed to the 
different samples used in UK and HK. The test-retest reliability of the UK study was derived from a university student sample, while the current study used a sample of mental health service users. The positive and significant $\mathrm{r}$-values and $\mathrm{K}$-values are within the range considered to be acceptable.

The same statistics analysis was undertaken between baseline and six months. The intention was to assess if any change took place. The $r$ values ranged from 0.22 to 0.98 and Kappa values ranged from 0.14 to 0.75 , showing significant relationships between the scores at the two time points (baseline and six months after). It was observed that most of the Kappa values and $r$ values between time 1 and time 3 were lower than that between time 1 and time 2 . Considerable drops were registered for satisfaction with opportunities for housing, finding someone to borrow money, frequency of visits to GP for physical health, and frequency of visits to hospital for mental health. This is probably due to the rising property price and rental in the period, and the situational changes of one's health and mental health. For other items, there were significant correlations between time 1 and time 3 indicating that conditions of the participants were stable over a six-month period.

The internal consistency of item scores and by dimensions, and their stability over time (two weeks after as well as six months after), has provided good evidence that the measurement tool is reliable. The similarities to the UK findings also lend support to both its initial suggestion that the scale migration is possible and the construct that the scale is supposed to measure is also identifiable in the East as it is in the West. While researchers cast lights on the uniqueness of the Eastern context, basic concerns such as social inclusion as measured by perceived and satisfaction with opportunities in the community are also measurable in the Asia. This will open up tremendous opportunities for meaningful comparative studies. 
To conclude, the present study demonstrated the application of a Chinese version of social inclusion (SCOPE-C) in measuring social inclusion among mental health services users. It also examined the two-week test-retest reliability of SCOPE-C and changes after six months. Results showed that the migration of English version SCOPE to SCOPE-C is feasible and appropriate. There was a great deal of commonality in the domains of inclusion/exclusion among the UK sample and the Hong Kong sample. Items in SCOPE-C had somewhat higher internal consistency and inter-item correlation than the original SCOPE. The prior focus group discussions and concept mapping have proved to be beneficial to the adaptation and migration of the instrument. Further work is required to assess change over time in people with acute mental health problems, and to examine aspects of validity using contemporary methods (Coaley, 2014; De Vellis, 2012). 


\section{References}

Chan, K., Evans, S., Ng, Y. L., Chiu, Y. L., \& Huxley, P. J. (2013). A concept mapping study on social inclusion in Hong Kong. Social Indicator Research. doi: 10.1007/s11205-0130498-1

Coaley, K. (2014), An Introduction to Psychological Assessment and Psychometrics, 2nd edition. Thousand Oaks, CA: Sage Publishing.

Curran, C., Burchardt, T., Knapp, M., McDaid D., \& Li, B. (2007). Challenges in multidisciplinary systematic reviewing: Improving the evidence base for social exclusion and mental health policy. Social Policy \& Administration, 41(3), 289-312. doi:10.1111/j.1467-9515.2007.00553.x

DeVellis, R.F. (2012), Scale Development Theory and Applications, 3rd edition. Thousand Oaks, CA: Sage Publishing.

Evans S., \& Huxley P. (2005) Adaptation, response shift and quality of life ratings in mentally well and unwell groups. Quality of Life Research, 14(7), 1719-1732. doi: $10.1007 / \mathrm{s} 11136-005-1742-1$

Hong Kong Census and Statistics Department (2012). 2011 Population Census - Main Report: Volume II. Retrieved from http://www.census2011.gov.hk/pdf/main-report-volumeII.pdf

Huxley, P., Evans, S., Munroe, M., \& Philpin, S. (2008). SCOPE for social inclusion? A Life in the Day, 12(3), 33-35. doi: 10.1108/13666282200800029.

Huxley, P., Evans, S., Munroe, M., Webber, M., Burchardt T., Knapp, M., \& McDaid, D. (2006). Development of a 'Social Inclusion Index' to capture subjective and objective domains (Phase I): Final report to NCCRM. Retrieved from http://www.hta.ac.uk/nihrmethodology/reports/1591.pdf

Huxley, P., Evans, S., Madge, S., Webber, M., Burchardt, T., McDaid, D., \& Knapp, M. (2012). Development of a social inclusion index to capture subjective and objective life domains (phase II): psychometric development study. Health Technology Assessment, 16(1), 1-248. doi: 10.3310/hta16010

The World Bank (2013). Social inclusion. Retrieved from http://www.worldbank.org/en/topic/socialdevelopment/brief/social-inclusion 